\section{Screening and Characterization of Novel Polyesterases from Environmental Metagenomes with High Hydrolytic Activity against Synthetic Polyesters} \\ Hajighasemi, Mahbod; Tchigvintsev, Anatoly; Nocek, Boguslaw; Flick, Robert; \\ Popovic, Anna; Hai, Tran; Khusnutdinova, Anna N.; Brown, Greg; Xu, Xiaohui; \\ Cui, Hong; Anstett, Julia; Chernikova, Tatyana; Bruls, Thomas; Le Paslier, \\ Denis; Yakimov, Michail M.; Joachimiak, Andrzej; Golyshina, Olga; Savchenko, \\ Alexei; Golyshin, Peter; Edwards, Elizabeth A.; Yakunin, A. F.

\section{Environmental Science and Technology} \\ DOI: \\ 10.1021/acs.est.8b04252
}

Published: 06/11/2018

Peer reviewed version

Cyswllt i'r cyhoeddiad / Link to publication

Dyfyniad o'r fersiwn a gyhoeddwyd / Citation for published version (APA):

Hajighasemi, M., Tchigvintsev, A., Nocek, B., Flick, R., Popovic, A., Hai, T., Khusnutdinova, A. N., Brown, G., Xu, X., Cui, H., Anstett, J., Chernikova, T., Bruls, T., Le Paslier, D., Yakimov, M. M., Joachimiak, A., Golyshina, O., Savchenko, A., Golyshin, P., ... Yakunin, A. F. (2018).

Screening and Characterization of Novel Polyesterases from Environmental Metagenomes with High Hydrolytic Activity against Synthetic Polyesters. Environmental Science and Technology, 52(21), 12388-12401. https://doi.org/10.1021/acs.est.8b04252

\footnotetext{
Hawliau Cyffredinol / General rights

Copyright and moral rights for the publications made accessible in the public portal are retained by the authors and/or other copyright owners and it is a condition of accessing publications that users recognise and abide by the legal requirements associated with these rights. study or research.

- Users may download and print one copy of any publication from the public portal for the purpose of private

- You may not further distribute the material or use it for any profit-making activity or commercial gain

- You may freely distribute the URL identifying the publication in the public portal ?
} 
1 Screening and characterization of novel polyesterases from environmental

2 metagenomes with high hydrolytic activity against synthetic polyesters

3 Mahbod Hajighasemi, ${ }^{1}$ Anatoli Tchigvintsev, ${ }^{1}$ Boguslaw Nocek, ${ }^{2}$ Robert Flick, ${ }^{1}$ Ana

4 Popovic, ${ }^{1}$ Tran Hai, ${ }^{3}$ Anna N. Khusnutdinova, ${ }^{1}$ Greg Brown, ${ }^{1}$ Xiaohui Xu, ${ }^{1}$ Hong Cui,${ }^{1}$

5 Julia Glinos, ${ }^{1}$ Tatyana N. Chernikova, ${ }^{3}$ Thomas Brüls, ${ }^{4}$ Denis Le Paslier, ${ }^{5}$ Michail M.

6 Yakimov, ${ }^{6}$ Andrzej Joachimiak, ${ }^{2}$ Olga V. Golyshina, ${ }^{3}$ Alexei Savchenko, ${ }^{1}$ Peter $N$.

7 Golyshin, ${ }^{3}$ Elizabeth A. Edwards, ${ }^{1}$ and Alexander F. Yakunin ${ }^{1 *}$

$9 \quad{ }^{1}$ Department of Chemical Engineering and Applied Chemistry, University of Toronto,

10 Toronto, ON, M5S 3E5, Canada

$11{ }^{2}$ Midwest Center for Structural Genomics and Structural Biology Center, Biosciences

12 Division, Argonne National Laboratory, Argonne, Illinois 60439, U.S.A.

$13{ }^{3}$ School of Biological Sciences, Bangor University, Gwynedd LL57 2UW, UK

$14{ }^{4}$ Commissariat à l'Energie Atomique et aux Energies Alternatives (CEA), Direction de

15 la Recherche Fondamentale, Institut de Génomique, Université de d'Evry Val

16 d'Essonne (UEVE), Centre National de la Recherche Scientifique (CNRS), UMR8030,

17 Génomique métabolique, Evry, France 
$18{ }^{5}$ Université de d'Evry Val d'Essonne (UEVE), Centre National de la Recherche

19 Scientifique (CNRS), UMR8030, Génomique métabolique, Commissariat à l'Energie

20 Atomique et aux Energies Alternatives (CEA), Direction de la Recherche

21 Fondamentale, Institut de Génomique, Evry, France

$22{ }^{6}$ Institute for Coastal Marine Environment, CNR, 98122 Messina, Italy

23 * Corresponding author: Email a.iakounine@ utoronto.ca; phone 416-978-4013; fax 416-

$24 \quad 978-8605$

25

26

27

28

29

30

31

32

33 


\section{ABSTRACT}

35 The continuous growth of global plastics production for more than 50 years has resulted

36 in elevated levels of pollution and serious environmental problems. Enzymatic

37 depolymerization of synthetic polyesters represents an attractive approach for plastics

38 recycling and effective use of carbon resources. In this study, screening of over 200

39 purified uncharacterized hydrolases from environmental metagenomes and sequenced

40 microbial genomes identified 27 proteins with detectable activity and at least 10 proteins

41 with high hydrolytic activity against synthetic polyesters. The metagenomic esterases

42 GEN0105 and MGS0156 were active against a broad range of synthetic polyesters

43 including polylactic acid, polycaprolactone, and bis(benzoyloxyethyl)-terephthalate. With

44 solid polylactic acid as substrate, both enzymes produced a mixture of lactic acid

45 monomers, dimers, and higher oligomers. The crystal structure of MGS0156 was

46 determined at $1.95 \AA$ resolution and revealed a modified $\alpha / \beta$ hydrolase fold, with a highly

47 hydrophobic active site and lid domain. Mutational studies of MGS0156 identified the

48 residues critical for hydrolytic activity against both monoester and polyester substrates,

49 and demonstrated a two-times higher polyesterase activity in the L169A mutant protein.

50 Thus, environmental metagenomes contain diverse polyesterases with high hydrolytic

51 activity against a broad range of synthetic polyesters with potential applications in

52 plastics recycling. 


\section{Introduction}

58 Over the last 50 years, global production of plastics has continuously increased,

59 reaching 322 million tons in $2015 .{ }^{1}$ Synthetic polymers have become indispensable to our

60 lives, with numerous applications in industry and everyday life. ${ }^{2,3}$ The six types of

61 plastics accounting for approximately $90 \%$ of the total demand include polyethylene (PE,

62 low-density and high-density PE), polypropylene (PP), polystyrene (PS), polyvinyl

63 chloride (PVC), polyethylene terephthalate (PET), and polyurethane (PUR). ${ }^{1,2}$ The

64 majority of plastics are made from petroleum and represent short-lived products (e.g.

65 packaging materials), which are disposed of within one year after manufacture. For

66 packaging plastics, it is estimated that only $28 \%$ of materials are collected for

67 recycling/incineration, while $30-40 \%$ are land filled, and the rest (30-40\%) appears to

68 escape the collection system. ${ }^{1,4}$ Most petroleum-based plastics have been considered to

69 be remarkably resistant to biological degradation. ${ }^{5,6}$ A tremendous increase in production

70 of synthetic polymers and their persistence in the environment resulted in elevated levels

71 of pollution and serious environmental problems. ${ }^{1,6}$ Therefore, production of

72 biodegradable plastics from renewable feedstocks represents a promising solution and has

73 become a focus of research.

74 Biodegradable synthetic polymers combine beneficial physical properties of polymers

75 with biodegradability, determined by the presence of hydrolysable backbones such as

76 polyesters, polycarbonates, polyurethanes and polyamides. ${ }^{6-8}$ In contrast, biodegradation

77 of PE, PP, PS and PVC is obstructed by the lack of hydrolysable bonds in their

78 backbones. Among synthetic polymers, aliphatic polyesters such as polylactic acid (PLA)

79 and polycaprolactone (PCL) are generally known to be susceptible to biological 
80 degradation, whereas aromatic polyesters (like polyethylene terephthalate (PET)) have

81 better mechanical properties, but are more resistant to microbial or enzymatic attack. ${ }^{4,9}$

82 Therefore, there is high interest in the development of different co-polyesters, including

83 aliphatic-aromatic co-polyesters, which combine excellent mechanical properties with

84 biodegradability, e.g. poly(butylene succinate-co-adipate (PBSA) and poly(butylene

85 adipate-co-terephthalate (PBAT). ${ }^{10}$ In general, biodegradability of synthetic polymers has

86 been determined by their hydrophobicity, degree of crystallinity, surface topography and

87 molecular size. ${ }^{6,7,11}$ Presently, PLA and starch-based polymers represent the two most

88 important commercial, biodegradable plastics accounting for about $47 \%$ and $41 \%$,

89 respectively. $^{12}$

90 The most sustainable option for plastics waste treatment is a closed-loop recycling

91 process based on the recovery of chemical feedstocks and their reuse for the synthesis of

92 novel polymers (a circular economy) (Andersen MS. Sustainability Science, 2007, 2:

93 133-140; Kubo). ${ }^{13,14}$ For the most effective use of carbon resources, it is ideal that

94 discarded plastic waste be restored to original raw materials using physical, chemical, or

95 enzymatic recycling. ${ }^{15}$ Compared to physical, thermal, and chemical plastics

96 depolymerization, biocatalytic (microbial or enzyme-based) recycling has several

97 advantages including low energy consumption, mild reaction conditions, and the

98 possibility for stereospecific degradation and enzymatic repolymerization. ${ }^{15}, 16$ In contrast

99 to complete plastics biodegradation to $\mathrm{CO}_{2}$, biocatalytic plastics recycling is aimed at

100 reusing the products generated by enzymatic treatment.

101 Various bacteria and fungi have been reported to degrade plastic materials in diverse

102 environmental conditions such as soils, sludges, composts, and marine water. ${ }^{10}$ Many 
103 aliphatic polyesters, including PLA and PCL, were found to be degraded by Aspergillus,

104 Penicillium, Pullularia, Trichoderma, and other fungal strains isolated from

105 environmental samples. ${ }^{17,18}$ Among bacteria, different strains of Bacillus, Pseudomonas,

106 Leptothrix, Roseateles, Corynebacterium, Streptomyces, and Enterobacter can efficiently

107 degrade both aliphatic and aliphatic-aromatic co-polyesters (e.g. PBAT). ${ }^{10,19}$ Most of the

108 biodegradable polyesters are degraded by serine-dependent hydrolases such as lipases,

109 esterases, proteases, and cutinases. ${ }^{10}$ Several polyester degrading lipases and esterases

110 have been characterized biochemically, including Paenibacillus amylolyticus PlaA,

111 Thermobifida fusca TfH, ABO1197 and ABO1251 from Alcanivorax borkumensis,

112 several clostridial esterases (Chath_Est1, Cbotu_EstA, Cbotu_EstB), and the

113 metagenomics polyesterases PlaM4, EstB3, and EstC7. ${ }^{20-25}$ Cutinases comprise a family

114 of serine hydrolases produced by bacteria, fungi, and plants, whose natural substrate is

115 the biopolyester cutin (a major component of plant cuticle). ${ }^{26}$ Several purified bacterial

116 (Thermobifida), fungal (Humicola, Aspegillus, Fusarium), and metagenomic cutinases

117 have been shown to hydrolyze synthetic polyesters including PET and polyurethane., ${ }^{47-}$

$118{ }^{30}$ Crystal structures have been determined for the thermophilic fungus Humicola insolens

119 cutinase HiC, metagenomic LC-cutinase from leaf-branch compost, as well as for the

120 polyester degrading esterases from Rhodopseudomonas palustris (RPA1511) and

121 Clostridium hathewayi (Chath_Est1). ${ }^{23,31-33}$ In contrast to lipases, polyesterase structures

122 revealed a wide-open active site directly accessible to polymeric substrates as shown by

123 the structure of RPA1511 in complex with polyethylene glycol bound close to the

124 catalytic triad. ${ }^{33}$ In addition, mutagenesis and protein engineering experiments with the 
125 Thermobifida cellulosilytica cutinases Thc_Cut1 and Thc_Cut2 demonstrated an

126 important role of enzyme surface and hydrophobic interactions for polyester hydrolysis. ${ }^{34}$

127 Although recent studies have identified a number of polyester degrading enzymes, the

128 continuously growing global demand for plastics and novel polymers has also stimulated

129 the interest in novel enzymes and biocatalytic approaches for polymer synthesis and

130 recycling technologies. The discovery of novel polymer degrading enzymes and

131 engineering of more active enzyme variants, as well as understanding of the molecular

132 mechanisms of these enzymes represent the key challenges for the development of

133 biocatalytic strategies for polymer hydrolysis and synthesis. ${ }^{1}$ In this work, we have

134 identified over 30 active metagenomic polyesterases through enzymatic screening, and

135 biochemically characterized MGS0156 and GEN0105, which showed high hydrolytic

136 activity against a broad range of polyesters (PLA, PCL, PET, PBSA, and PES). The crystal

137 structure of MGS0156 revealed an open active site with hydrophobic surface, whereas

138 structure-based mutagenesis studies identified amino acid residues critical for enzymatic

139 activity.

140

141 MATERIALS AND METHODS

142 Reagents. All chemicals and substrates used in this study were of analytical grade

143 unless otherwise stated. Polymeric substrates were purchased from Sigma-Aldrich (St.

144 Louis, MO, USA) except poly (D,L-lactide) PLA2 $\left(\mathrm{M}_{\mathrm{w}} 0.2 \times 10^{4}\right)$, PLA70 $\left(\mathrm{M}_{\mathrm{w}} 7.0 \times\right.$

$\left.14510^{4}\right)$, and poly (L-lactide) PLLA40 $\left(\mathrm{M}_{\mathrm{w}} 4.0 \times 10^{4}\right)$, that were obtained from PolySciTech

146 (Akina Inc., West Lafayette, IN, USA). Commercial-grade PLA polymers (Ingeo ${ }^{\mathrm{TM}}$

147 4032D, and Ingeo ${ }^{\mathrm{TM}}$ 6400D) were products of NatureWorks LLC (NE, USA), poly (D- 
148 lactide) PURASORB ${ }^{\mathrm{TM}}$ PD 24 of Corbion Purac (Amsterdam, The Netherlands), whereas

149 polybutylene succinate (PBS) (Bionolle ${ }^{\mathrm{TM}} 1001 \mathrm{MD}$, and Bionolle $\left.{ }^{\mathrm{TM}} 1020 \mathrm{MD}\right)$ and

150 polybutylene succinate-co-adipate (PBSA) $\left(\right.$ Bionolle $^{\mathrm{TM}} 3001 \mathrm{MD}$, and Bionolle ${ }^{\mathrm{TM}}$

151 3020MD) were purchased from Showa Denko K.K., Japan. The surfactant Plysurf

152 A210G was obtained from Dai-ichi Kogyo Seiyaku Co. (Tokyo, Japan) and used to

153 emulsify the polymers.

154 Gene cloning, protein purification, and mutagenesis. For recombinant expression,

155 the coding sequences of selected hydrolase genes were PCR amplified and cloned into a

156 modified pET15b (Novagen) vector containing an $\mathrm{N}$-terminal 6His tag as described

157 previously. ${ }^{35}$ Since full length MGS0156 (1-421 aa) showed low expression in E. coli, a

158 truncated variant of this protein (75-421 aa) with the $\mathrm{N}$-terminal signal peptide removed

159 was used. Recombinant proteins were overexpressed in Escherichia coli BL21 (DE3)

160 Codon-Plus strain (Stratagene) and purified to near homogeneity (>95\%) using metal-

161 chelate affinity chromatography on Ni-NTA Superflow $\left(\mathrm{Ni}^{2+}\right.$-nitrilotriacetate) resin

162 (Qiagen). Size exclusion chromatography was performed using a HiLoad 16/60 Superdex

163200 column (GE Healthcare) equilibrated with $10 \mathrm{mM}$ HEPES (pH 7.5), $0.25 \mathrm{M} \mathrm{NaCl}$

164 and $1 \mathrm{mM}$ TCEP [tris-(2-carboxyethyl)phosphine]. ${ }^{36}$ The L-lactate dehydrogenase

165 (PfLDH) from Plasmodium falciparum ${ }^{37}$ and the D-lactate dehydrogenase (D-LDH3)

166 from Lactobacillus jensenii ${ }^{38}$ (used in lactate assays) were heterologously expressed in $E$.

167 coli and affinity purified to near homogeneity. Site-directed mutagenesis of

168 metagenomics esterases was performed using a QuickChange ${ }^{\circledR}$ kit (Stratagene) according

169 to the manufacturer's protocol. Wild-type MGS0156 and GEN0105 were used as the

170 templates, and mutations were verified via DNA sequencing. The selected residues were 
171 mutated to Ala or Gly (for Ala replacements producing insoluble proteins). Mutant

172 proteins were overexpressed and purified in the same manner as described for the wild-

173 type proteins. Multiple sequence alignment was conducted by Clustal Omega v1.2.1

174 through EMBL-EBI server, whereas phylogenetic analysis was performed by MEGA

175 v7.0 using the neighbor-joining method. ${ }^{39,40}$

176 Esterase assays with soluble substrates. Carboxylesterase activity was measured

177 spectrophotometrically as described previously. ${ }^{35}$ Purified enzymes (0.05-10.0 $\mu \mathrm{g}$

178 protein/reaction) were assayed against $\alpha$-naphthyl or $p$-nitrophenyl ( $p$ NP) esters of

179 different fatty acids $(0.25-2.0 \mathrm{mM})$ as substrates in a reaction mixture containing $50 \mathrm{mM}$

180 HEPES-K buffer ( $\mathrm{pH} 8.0) \cdot{ }^{35}$ Reaction mixtures (200 $\mu$, in triplicate) were incubated at

$18130{ }^{\circ} \mathrm{C}$ in a 96-well plate format. Enzyme kinetics were determined by substrate saturation

182 curve fitting (non-linear regression) using GraphPad Prism software (version 7.0 for Mac,

183 GraphPad Software, CA, USA).

184 Polyester degradation (polyesterase) screens. Emulsified polyester substrates were

185 prepared in $50 \mathrm{mM}$ Tris- $\mathrm{HCl}$ buffer $(\mathrm{pH} 8.0)$, containing agarose $(1.5 \%, \mathrm{w} / \mathrm{v})$, and plate

186 polyesterase assays were performed using $50-100 \mu \mathrm{g}$ of purified protein/well $\left(30^{\circ} \mathrm{C}\right)$ as

187 described previously. ${ }^{33,41}$ The presence of polyesterase activity was inferred from the

188 formation of a clear halo around the wells with purified proteins. ${ }^{33,41}$

189 Analysis of the reaction products of solid PLA depolymerization. Purified enzymes

$190(50 \mu \mathrm{g})$ were incubated with PLA10 powder $(10-12 \mathrm{mg})$ in a reaction mixture $(1 \mathrm{ml})$

191 containing $0.4 \mathrm{M}$ Tris- $\mathrm{HCl}$ buffer (pH 8.0) for $18 \mathrm{hr}$ at $30^{\circ} \mathrm{C}$ with shaking. Supernatant

192 fractions were collected at different time points, clarified using centrifugal filters

193 (MWCO $10 \mathrm{kDa}$ ), and the produced lactic acid was measured using lactate 
194 dehydrogenase (LDH) as described previously. ${ }^{33,42}$ For the analysis of oligomeric PLA

195 products in supernatant fractions (passed through $10 \mathrm{kDa}$ filters), the flow-through

196 aliquots $(90 \mu \mathrm{l})$ were treated for $5 \mathrm{~min}$ at $95^{\circ} \mathrm{C}$ with $1 \mathrm{M} \mathrm{NaOH}$ (final concentration) to

197 convert oligomeric PLA products to lactic acid monomers before lactate measurements

198 using both L- and D-LDHs (the data were corrected for the presence of monomeric lactic

199 acid before the alkaline treatment). Both LDH enzymes were added to the reaction

200 mixture in excess (total $500 \mu \mathrm{g} / \mathrm{ml}, 50 / 50$ ) to maintain the reaction rate in the first order

201 with lactate concentration. To identify the water-soluble products of PLA hydrolysis, the

202 filtered supernatant fractions from solid PLA reactions were analysed using reverse phase

203 liquid chromatography, ${ }^{43}$ coupled with mass spectrometry (LC-MS). The platform

204 configuration and methodology were as described previously. ${ }^{33}$

205 Protein crystallization and crystal structure determination of MGS0156. Purified

206 MGS0156 (75-421 aa) was crystallized at room temperature using the sitting drop vapor

207 diffusion method by mixing $1 \mu \mathrm{l}$ of the selenomethionine substituted protein $(12 \mathrm{mg} / \mathrm{ml})$

208 with $1 \mu \mathrm{l}$ of crystallization solution containing $30 \%$ (w/v) PEG 4k, $0.2 \mathrm{M}$ ammonium

209 acetate, $0.1 \mathrm{M}$ sodium citrate ( $\mathrm{pH}$ 5.6), and 1/70 chymotrypsin. Crystals were harvested

210 using mounted cryo-loops and transfered into the cryo-protectant (Paratone-N) prior to

211 flash-freezing in liquid nitrogen. Data collections were carried out at the beamlines 19-ID

212 of the Structural Biology Center, Advanced Photon Source, Argonne National

213 Laboratory. ${ }^{44}$ The data set was collected from a single crystal to $1.95 \AA$ at the wavelength

214 of $0.9794 \AA$ and processed using the program HKL3000 ${ }^{45}$ (Table S1). The structure of

215 MGS0156 was determined by the Se-methionine SAD phasing, density modification, and

216 initial model building as implemented in the PHENIX suite of programs. ${ }^{46}$ The initial 
217 models ( $~ 90 \%$ complete) were further built manually using the program $\mathrm{COOT}^{47}$ and

218 refined with PHENIX. Analysis and validation of structures were performed using

219 MOLPROBITY ${ }^{48}$ and COOT validation tools. The final model was refined to

$220 \mathrm{R}_{\mathrm{work}} / \mathrm{R}_{\mathrm{free}}=0.1532 / 0.19$, and it shows good geometry with no outliers in the

221 Ramachandran plot. Data collection and refinement statistics are summarized in Table

222 S1. Surface electrostatic charge analysis was performed using the APBS tool in Pymol on

223 a model generated by the PDB2PQR server. ${ }^{49,} 50$ The topology diagram of MGS0156 was

224 generated by HERA program ${ }^{51}$ through PDBsum server. ${ }^{52}$ The atomic coordinates have

225 been deposited in the Protein Data Bank, with accession code 5D8M.

227 RESULTS AND DISCUSSION

228 Screening of purified microbial hydrolases for polyesterase activity. To discover

229 novel polyesterases, 213 purified uncharacterized hydrolases (Table S2) from

230 environmental metagenomes and sequenced microbial genomes were screened for

231 hydrolytic activity against emulsified PLA10 [poly (DL-lactide); $\mathrm{M}_{\mathrm{w}} 10 \mathrm{~K}$ ], PLLA40

232 [poly(L-lactide); $\left.\mathrm{M}_{\mathrm{w}} 40 \mathrm{~K}\right]$, polycaprolactone PCL10 ( $\left.\mathrm{M}_{\mathrm{w}} 10 \mathrm{~K}\right)$, and

233 bis(benzoyloxyethyl) terephthalate (3PET) using agarose-based screens. These screens

234 revealed the presence of detectable polyesterase activity in 37 proteins, mostly from the

$235 \alpha / \beta$ hydrolase superfamily (Table S3). Most of these proteins were active against PLA10?

236 (22 proteins), 3PET (13 proteins), and PCL (11 proteins), whereas nine proteins exhibited

237 activity toward poly(L-lactide) (PLLA40). Thus, a significant number of microbial and

238 metagenomic hydrolases exhibit hydrolytic activity against synthetic polyesters. 
239 The present work is focused on the biochemical characterization of the metagenomic

240 polyesterases GEN0105 and MGS0156, which showed high hydrolytic activity against

241 PLA10, PCL10, and 3PET (Figure 1). Carboxyl esterase activity of these enzymes was

242 initially identified using tributyrin-based esterase screens of the metagenomic gene

243 libraries from an anaerobic urban waste degrading facility (GEN0105) or paper mill

244 waste degrading microbial community (MGS0156). ${ }^{53}$

245 The MGS0156 gene encodes a protein comprised of 421 amino acids with a potential

246 N-terminal signal peptide (1-75 aa), whereas the GEN0105 sequence (322 aa) appears to

247 lack an obvious signal peptide (Figure S1). Based on sequence analysis, both GEN0105

248 and MGS0156 belong to serine dependent $\alpha / \beta$ hydrolases, but share low sequence

249 identity to each other $(21.1 \%)$. Both enzymes represent metagenomic proteins as

250 GEN0105 shares 61\% sequence identity with the predicted esterase B0L3I1_9BACT

251 from an uncultured bacterium, whereas the closest homologue of MGS0156

252 (DesfrDRAFT_2296 from Desulfovibrio fructosivorans) shows 71\% sequence identity to

253 this protein (Figure S1). Phylogenetic analysis revealed that GEN0105 is associated with

254 esterase family IV, which also includes the cutinase-like polyesterase CLE from

255 Cryptococcus sp. strain S-2 (Figure 2). ${ }^{54,55}$ In contrast, MGS0156, as well as MGS0084

256 and GEN0160 showed no clustering with known families of lipolytic enzymes,

257 suggesting that these proteins represent new esterase families (Figure 2). Thus, the type II

258 (lipase/cutinase type) polyesterases, including PLA depolymerases, exhibit broad

259 phylogenetic diversity and are associated with esterase families I, III, IV, V as well as

260 with new esterase families. 
262 Carboxyl esterase activity of GEN0105 and MGS0156 against soluble monoester

263 substrates. The acyl chain length preferences of purified recombinant GEN0105 and

264 MGS0156 (75-421 aa) were characterized using spectrophotometric assays with $\alpha$ -

265 naphthyl and $p$-nitrophenyl ( $p$ NP) monoesters (Figure 3). For these substrates, GEN0105

266 was most active against $\alpha$-naphthyl butyrate, $p \mathrm{NP}$-butyrate and $p \mathrm{NP}$-valerate (C4 and

267 C5 substrates). Compared to GEN0105, the specific activity of MGS0156 was an order of

268 magnitude greater with a preference for longer (C8-C10) substrates (Figure 3). MGS0156

269 also exhibited significant hydrolytic activity against $p$ NP-palmitate (C16) (Figure 3),

270 which is in line with the lipolytic activity of this protein against olive oil observed in

271 agar-based screens (data not shown), indicating that it is a lipase-like enzyme. With

272 monoester substrates, both enzymes demonstrated saturation kinetics with MGS0156

273 showing high catalytic efficiencies with low $K_{\mathrm{m}}$ values toward a broad range of substrates

274 (Table 1).

275 Based on temperature profiles of esterase activity, both GEN0105 and MGS0156 are

276 mesophilic esterases showing maximal activity between $35-40^{\circ} \mathrm{C}$ and retained

277 approximately $20 \%$ of maximal activity at $5^{\circ} \mathrm{C}$ (Figure S2). This is similar to the

278 mesophilic esterase BioH from E. coli, whereas the cold-resistant esterase OLEI01171

279 from Oleispira antarctica was most active at $20^{\circ} \mathrm{C}$ and retained $82 \%$ of its maximal

280 activity at $5^{\circ} \mathrm{C} .{ }^{36}$ In addition, GEN0105 and MGS0156 showed similar sensitivity to

281 inhibition by detergents (Triton X-100 and Tween 20), whereas MGS0156 retained

282 higher residual activity $(25-75 \%)$ in the presence of salts $(0.5-2.5 \mathrm{M} \mathrm{NaCl}$ or $\mathrm{KCl})$

283 (Figure S2). Thus, with monoester substrates, GEN0105 and MGS0156 exhibit different 
284 acyl chain length preferences and salt resistances, but similar sensitivities to temperature

285 and detergents.

287 Hydrolytic activity of metagenomics polyesterases against 22 polyester substrates.

288 The polyester substrate ranges of purified GEN0105 and MGS0156 were determined

289 using agarose-based assays with 22 emulsified synthetic polyesters, including PLA and

290 PCL, with different molecular weights and compositions, as well as their copolymers and

291 3PET (Table 2). Polyesterase activity of these enzymes was compared with the activity of

292 the recently identified metagenomic esterases GEN0160 and MGS0084. ${ }^{53}$ As shown in

293 Figure 1, the four metagenomic esterases exhibited polyesterase activity against

294 emulsified PCL10, which was higher or comparable to that of the previously identified

295 polyesterase PlaM4 from compost. ${ }^{24}$ When screened against 22 emulsified polyesters,

296 GEN0105 and MGS0156 degraded 17 and 13 substrates, respectively, including PLA,

297 PLGA (full name?), PCL, PBSA, and 3PET (Table 2). Both enzymes hydrolyzed the

298 majority of the tested PLA polymers, with GEN0105 displaying activity against poly(L-

299 lactide) and neither enzyme displaying activity against poly(D-lactide). Previously, it has

300 been shown that type I (protease) PLA depolymerases are specific toward poly(L-

301 lactide), as opposed to type II (cutinase/lipase) PLA depolymerases, which show

302 preference for poly(DL-lactide) ${ }^{56,57}$ Besides GEN0105, only the cutinase-like type II

303 enzyme CLE from Cryptococcus sp. strain S-2 has been shown to be able to hydrolyze

304 poly(L-lactide). ${ }^{54,56}$ PLA substrates with the acid end protected by the addition of an

305 ester group were also hydrolyzed by GEN0105 and MGS0156, suggesting that these

306 polyesterases can exhibit endo-type hydrolysis. In contrast, GEN0160 and MGS0084 
307 showed no polyesterase activity against PLA substrates (except for MGS0084 toward

308 PLA2) and 3PET (Table 2). Finally, the four metagenomic esterases showed no

309 hydrolytic activity toward poly(D-lactide), PHB and PBS. Thus, GEN0105 appears to be

310 the most versatile polyesterase from the four tested enzymes, being able to hydrolyze a

311 copolymer of hydroxybutyric acid and hydroxyvaleric acid (PHBV), as well as the

312 commercial polymer Ingeo $^{\mathrm{TM}}$ PLA6400 from NatureWorks (Table 2).

314 Analysis of the reaction products of solid PLA hydrolysis. To demonstrate hydrolytic

315 activity of the identified metagenomic polyesterases against solid PLA substrates,

316 purified MGS0156 and GEN0105 were incubated with solid poly(DL-lactide)

317 (PLA10???) powder suspended in $0.4 \mathrm{M}$ Tris- $\mathrm{HCl}$ buffer. At indicated time points

318 (Figure 4), reaction mixture aliquots were cleared using centrifugal filters (MWCO 10

$319 \mathrm{kDa}$ ), and the production of monomeric and oligomeric lactic acid products was analyzed

320 using L- and D-lactate dehydrogenases (as described in Materials and Methods). After 6

321 hours of incubation at $30{ }^{\circ} \mathrm{C}$, MGS0156 hydrolyzed approximately $80 \%$ of the solid PLA

322 substrate producing a mixture of oligomeric and monomeric products (Figure 4). The

323 proportion of monomeric lactic acid product increased with longer incubation times

324 resulting in almost full (95\%?) conversion of solid PLA substrate (monomeric +

325 oligomeric products) after overnight incubation (Figure 4). GEN0105 degraded $~ 70 \%$ of

326 solid PLA after overnight incubation, but was able to produce significant amounts of

327 lactic acid within the first $30 \mathrm{~min}$ of incubation (Figure 4). The presence of significant

328 amounts of oligomeric products during incubation of MGS0156 and GEN0105 with solid

329 PLA (Figure 4) also suggests that they can catalyze both endo- and exo-esterase cleavage 
330 of polyester substrates. Liquid chromatography-mass spectrometry (LC-MS) was used for

331 direct analysis of water-soluble reaction products from solid PLA hydrolysis by

332 MGS0156 and GEN0105 (Figure 5). The soluble reaction products were separated using

333 a C18 column and analyzed using mass spectrometry. These analyses revealed that both

334 enzymes produced mixtures of lactic acid monomers and oligomers with different chain

335 lengths (Figure 5 and Table S4). In line with the results of LDH-based assays, GEN0105

336 showed a higher degree of monomeric products compared to lactic acid oligomers,

337 suggesting that it may preferentially hydrolyze short chain substrates (Figure 4).

338 Recently, we have found that the purified polyesterase ABO2449 from Alcanivorax

339 borkumensis required the addition of detergents (e.g. 0.1\% Plysurf A210G) for solid PLA

340 hydrolysis, suggesting that detergents can facilitate protein binding to solid PLA. ${ }^{33}$

341 However, in this work detergents (0.1\% Plysurf A210G or Triton X-100) significantly

342 reduced hydrolytic activity of MGS0156 against solid PLA, and had no effect on

343 polyesterase activity of GEN0105 (data not shown). With monoester substrates,

344 GEN0105 retained significant catalytic activity in the presence of up to $20 \%$ detergent,

345 whereas MGS0156 was much more sensitive to detergents (Figure S2). Thus,

346 metagenomic polyesterases show different kinds of responses to detergents.

348 Crystal structure and active site of MGS0156. Purified metagenomic esterases

349 (GEN0105, GEN0160, MGS0084, and MGS0156) were submitted for crystallization

350 trials, with only MGS0156 (75-421 aa) producing diffracting crystals (Materials and

351 Methods). The crystal structure of the seleno-methionine-substituted MGS0156 was

352 solved at $1.95 \AA$ A resolution (Table S1), and revealed a protomer with an $\alpha / \beta$-hydrolase 
353 fold comprised of a slightly twisted central $\beta$-sheet with seven parallel $\beta$-strands (-5x, -

$\left.3541 \mathrm{x}, 2 \mathrm{x},(1 \mathrm{x})_{3}\right)$ and $19 \alpha$-helices (Figure 6A and Figure S3). The predicted catalytic

355 nucleophile Ser232 is positioned on a short sharp turn (the nucleophilic elbow) between

356 the $\beta 4$ strand and $\alpha 8$ helix. It is located at the bottom of the MGS0156 active site, which

357 is partially covered by a ring-shaped lid domain formed by seven short $\alpha$-helices ( $\alpha 4$,

$358 \alpha 10, \alpha 11, \alpha 14, \alpha 15, \alpha 16$, and $\alpha 18$ ) connected by flexible loops (Figure 6A).

359 Analysis of the MGS0156 crystal contacts using the quaternary prediction server PISA

360 suggested that this protein may form tetramers in solution through dimerization of dimers

361 (Figures 6B, C). The tetrameric state of MGS0156 is consistent with the results of size-

362 exclusion chromatography, which revealed a predominance for MGS0156 tetramers

363 (70\%), as well as the presence of some octomeric (25\%) and monomeric (5\%) forms (151

$364 \mathrm{kDa}, 296 \mathrm{kDa}$, and $40 \mathrm{kDa}$; predicted Mw $39 \mathrm{kDa}$ ). The tightly packed MGS0156 dimer

365 is created through multiple interactions between residues located on several $\alpha$-helices $(\alpha 1$,

$366 \alpha 2, \alpha 10, \alpha 13$, and $\alpha 16$ ) and the $\beta 1$ strand (buried area $4,100 \AA^{2}$, surface area $24,590 \AA^{2}$ ).

367 The two MGS0156 dimers are assembled into a tetramer via interactions between the

$368 \alpha 11, \alpha 15$, and $\alpha 18$ helices (surface area 47,980 $\AA^{2}$, buried area 9,400 $\AA^{2}$ ) (Figure 6C). In

369 the MGS0156 tetramer, the four active sites are not adjacent to each other and are

370 separated from the monomer interfaces with the two active site cavities open on the wide

371 sides of the oligomeric assembly (Figure 6C).

372 A structural homology search of the DALI and PDBeFold databases revealed hundreds

373 of structurally homologous proteins, mostly lipases and carboxylesterases with low

374 overall sequence similarity to MGS0156 ( $<20 \%$ sequence identity). The top structural

375 homologues include the LipA lipases from Pseudomonas aeruginosa (PA2862) (PDB 
376 code 1EX9, Z-score 24.3, rmsd $2.5 \AA$ A, 17\% identity) and Burkholderia cepacia (PDB

377 code 1OIL, Z-score 24.2, rmsd 2.6, $16 \%$ identity), as well as the Staphylococcs hyicus

378 lipase Lip (PDB code 2HIH, Z-score 23.2, RMSD $1.89 \AA$ A, 13\% identity). This Dali

379 search also identified structurally homologous polyesterases from Clostridium

380 botulinum $^{58}$ (PDB code 5AH1, Z-score 22.3, rmsd 2.6 Å, 15\% identity) and Pelosinus

381 fermentans $^{59}$ (PDB code 5AH0, Z-score 21.4, rmsd $2.5 \AA ̊$, 18\% identity).

382 The lid domain of MGS0156 contains many hydrophobic residues creating a

383 hydrophobic surface extending to the catalytic site cavity (Figure S4). The lid domain is

384 additionally stabilized by a disulfide bond between the Cys173 and Cys287 (Figure 7).

385 Disulfide bonds are not very common in esterase-type polyester hydrolases, with just a

386 few reports restricted to fungal cutinases (from A. oryzae ${ }^{60}, F$. solani $^{61}$, and

387 Cryptococcus sp. strain S-2 ${ }^{55}$ ). However, in cutinases the disulfide bond is involved in the 388 stabilization of the protein core domain.

389 The MGS0156 structure revealed two conformations for the catalytic Ser232 side

390 chain, one of which is hydrogen bonded to the N\&2 atom of the catalytic His373 (3.2 $\AA$ ),

391 whereas the other one is a bit further away $(3.9 \AA)$ and appears to be $\mathrm{H}$-bonded to the

392 backbone amide of Lys233 (2.7 $\mathrm{A}$ ) (Figure 7). This is similar to the recently reported two

393 conformations for the catalytic Ser130 of the naproxen esterase from Bacillus subtilis,

394 representing the resting and acting states of the active site. ${ }^{62}$ Like in known $\alpha / \beta$

395 hydrolases, the catalytic His373 of MGS0156 is supposed to act as a base, deprotonating

396 the Ser232 side chain to generate a nucleophilic alkoxide group. The MGS0156 structure

397 also indicates that the third member of its catalytic triad is Asp350 (2.8 $\AA$ to His373),

398 whereas its oxyanione hole appears to include the main chain $\mathrm{NH}$ groups of Lys 233 and 
399 Leu169 (2.7 Å and $3.8 \AA$ to Ser232, respectively) (Figure 7). The composition of the

400 MGS0156 catalytic triad (Ser232, His373, and Asp350) was confirmed using site-

401 directed mutagenesis, demonstrating that alanine replacement of these residues produced

402 catalytically inactive proteins (Figure 8). Like other biochemically characterized carboxyl

403 esterases, ${ }^{23,33,36,63}$ MGS0156 has a hydrophobic acyl-binding pocket formed by the side

404 chains of Leu169, Phe271, Leu275, Phe278, Leu299, Phe338, and Val353 (Figure 7).

405 The alcohol-binding pocket of the MGS0156 active site is located near the catalytic

406 Ser232 and is also filled mostly with hydrophobic residues, including Leu170, Val174,

407 Ile334, Met378, Phe380, and Ile391 (Figure 7).

408 Since GEN0105 failed to produce diffracting crystals, a structural model of this protein

409 was generated using the Phyre2 server ${ }^{64}$ and was used as a guide to identify its catalytic

410 residues (Figure S5). The structural model of GEN0105 revealed a classical $\alpha / \beta$ hydrolase

411 fold for this protein, with Ser168 as the nucleophilic serine in a conserved GXSXG motif

412 (Figure S5). The other two residues of the GEN0105 catalytic triad are His292 (3.1

413 from Ser168) and Glu262 (2.7 Å from His292). The catalytic role of these residues in

414 GEN0105 activity was confirmed using site-directed-mutagenesis (data not shown).

416 Structure-based site-directed mutagenesis of MGS0156. To identify the residues of

417 MGS0156 important for polyesterase activity, 30 active site residues were mutated to Ala

418 or Gly using site-directed mutagenesis. Hydrolytic activities of purified mutant proteins

419 were compared against wild-type protein activity using assays with $\alpha$-naphthyl acetate,

420 emulsified PCL10, and solid PLA10 as substrates (Figure 8). As expected, these assays

421 revealed a critical role of the MGS0156 catalytic triad (Ser232, His373, and Asp350) for 
422 hydrolysis of all tested substrates (Figure 8). These assays also demonstrated the

423 importance of three residues adjacent to the catalytic Ser232 (His231 and Lys233) and

424 His373 (Asp372) $(3.7-5.0 \AA$ ), which show strong sequence conservation (Figure 8 and

425 Figure S1). The side chains of conserved Cys173 and Cys287 form a disulfide bridge

426 stabilizing the protein lid domain, with alanine replacement of these residues reducing the

427 hydrolytic activity of MGS0156 toward all substrates (Figures 7 and 8). In addition,

428 enzymatic activity of MGS0156 against both mono- and polyesters was found to be

429 significantly reduced in the L299G, L335A, and M378G mutant proteins, which are

430 located in the active site cleft, likely contributing to substrate binding (Figures 7 and 8).

431 Reduced monoesterase activity was also observed in the L169A, L170G, E172G, V174G,

432 S265A, L352G, and F380G mutant proteins (Figure 8). The polyesterase activity of these

433 mutant proteins appeared to be unaffected based on agarose screens with emulsified

434 PCL10, but was reduced (except for L169A and S265A) in LDH-coupled assays with

435 solid PLA10 (Figure 8). These results suggest that the LDH-coupled polyesterase assay is

436 more sensitive than the agarose-based screen. In addition, the LDH-coupled assay with

437 solid PLA10 revealed a greatly diminished polyesterase activity in E330A, L335A,

438 F338G and V353A mutant proteins, whereas their activity toward $\alpha$-naphthyl acetate was

439 close to that of the wild-type protein or slightly reduced (Figure 8B). Finally, the

440 polyesterase and monoesterase activities of MGS0156 were not significantly effected in

441 the mutant proteins S175G, L179G, L197G, R199G, F271G, R277G, or E280G,

442 suggesting that these residues are not essential for substrate binding or enzymatic 443 activity. 
444 Interestingly, LDH-based assays with solid PLA10 revealed a two-fold increase in

445 polyesterase activity of L169A, whereas its monoesterase activity was reduced to

446 approximately $20 \%$ of the wild-type protein (Figure 8). As shown in Figure 4C,

447 following three hours of incubation with solid PLA10 the L169A mutant protein

448 demonstrated at least $90 \%$ substrate conversion to monomeric and oligomeric products,

449 whereas the wild-type enzyme hydrolyzed only 50\% of substrate. In the MGS0156

450 active site, the side chain of L169 is located close to the catalytic Ser232 (6.4 A) and can

451 potentially contribute to substrate binding/coordination (Figure Active site). Furthermore,

452 the L169G mutant protein showed lower polyesterase activity against PLA10 and PCL10

453 compared to L169A, both in LDH- and agarose-based assays (data not shown).

454 Therefore, we propose that hydrophobic interactions with polyester substrates at the

455 position of Leu169 are important for polyesterase activity, with the Ala side chain

456 providing better environment (reduced steric hindrance) for polyester binding) compared 457 to Leu.

458 Recently, we have determined the crystal structure and identified eight residues critical 459 for PLA hydrolysis by the R. palustris polyesterase RPA1511, which belongs to esterase 460 family V (Figure 2) ${ }^{33}$ However, structural superposition of this protein with MGS0156

461 revealed only two apparently homologous residues in MGS0156: Leu296 (Leu212 in

462 RPA1511) and Leu299 (Leu220 in RPA1511). While mutagenesis of Leu299 (to Gly)

463 abolished both polyesterase and monoesterase activities of MGS0156, replacement of

464 Leu296 (by Gly) had no significant effect on either activity (Figure 8). Thus, our results

465 indicate that although polyesterases from different esterase families have distinct binding 
466 modes for polyesters, their active sites contain a significant number of hydrophobic

467 residues which play an important role in substrate hydrolysis.

468 In summary, enzymatic screening of purified hydrolases and carboxyl esterases from

469 environmental metagenomes and microbial genomes revealed a large number of enzymes

470 with hydrolytic activity against various synthetic polyesters. These enzymes are adapted

471 to function under different experimental conditions reflecting the corresponding

472 environmental conditions of microbial communities. The biochemical and structural

473 characterization of novel polyesterases from environmental metagenomes advances our

474 understanding of enzymatic hydrolysis of synthetic polyesters and contributes to the

475 development of enzyme-based plastic recycling.

476

477 ASSOCIATED CONTENT

478 Supporting Information

479 The Supporting Information is available free of charge on the ACS Publications website

480 at DOI: The Supplemental file includes Table S1-S??? and Figures S1-S???

481

482 ACKNOWLEDGEMENTS

483 This work was supported by the Government of Canada through Genome Canada, the 484 Ontario Genomics Institute (2009-OGI-ABC-1405), Ontario Research Fund (ORF-GL2485 01-004), and the NSERC Strategic Network grant IBN. Structural work presented in this 486 paper was performed at Argonne National Laboratory, Structural Biology Center at the

487 Advanced Photon Source. Argonne is operated by UChicago Argonne, LLC, for the U.S. 488 Department of Energy, Office of biological and Environmental Research under contract 
DE-AC02-06CH11357. This work was also supported by European Community project

MAMBA (FP7-KBBE-2008-226977), MAGIC-PAH (FP7-KBBE-2009-245226),

491

ULIXES (FP7-KBBE-2010-266473), MicroB3 (FP7-OCEAN.2011-2-287589), KILL-

492

SPILL (FP7-KBBE-2012-312139), EU Horizon 2020 Project INMARE (Contract Nr

493

634486) and ERA Net IB2 Project MetaCat through UK Biotechnology and Biological

494 Sciences Research Council (BBSRC) Grant BB/M029085/1.

495

496

497

\section{References}

498 1. Wei, R.; Zimmermann, W., Microbial enzymes for the recycling of recalcitrant 499 petroleum-based plastics: how far are we? Microb Biotechnol 2017.

$500 \quad 2 . \quad$ Andrady, A. L.; Neal, M. A., Applications and societal benefits of plastics. Philos $501 \quad T R$ Soc B 2009, 364, (1526), 1977-1984.

502 3. Andrady, A. L., Microplastics in the marine environment. Mar Pollut Bull 2011, 503 62, (8), 1596-605.

504 4. Wei, R.; Zimmermann, W., Biocatalysis as a green route for recycling the 505 recalcitrant plastic polyethylene terephthalate. Microb Biotechnol 2017.

5065 5. Andrady, A. L., Assessment of environmental biodegradation of synthetic 507 polymers. J. Macromol. Sci. C 1994, 34, (1), 25-76.

508 6. Tokiwa, Y.; Calabia, B. P.; Ugwu, C. U.; Aiba, S., Biodegradability of plastics. 509 Int J Mol Sci 2009, 10, (9), 3722-42.

$5107 . \quad$ Restrepo-Florez, J.-M., Bassi, M., and Thompson, M.R., Microbial degradation 511 and deterioration of polyethylene - a review. Int. Biodeterior. Biodegradation 2014, 88, $51283-90$.

$513 \quad 8 . \quad$ Krueger, M. C.; Harms, H.; Schlosser, D., Prospects for microbiological solutions 514 to environmental pollution with plastics. Appl Microbiol Biotechnol 2015, 99, (21), 885751574.

5169 9. Tokiwa, Y.; Suzuki, T., Hydrolysis of polyesters by lipases. Nature 1977, 270, 517 (5632), 76-8.

518 10. Shah, A. A.; Kato, S.; Shintani, N.; Kamini, N. R.; Nakajima-Kambe, T., 519 Microbial degradation of aliphatic and aliphatic-aromatic co-polyesters. Appl Microbiol 520 Biot 2014, 98, (8), 3437-3447.

521 11. Webb, H., Arnott, J., Crawford, R., and Ivanova, E., Plastic degradation and its 522 environmental implications with special reference to poly(ethylene terephthalate).

523 Polymers 2013, 5, 1.

524 12. Ashter, S. A., Introduction to Bioplastics Engineering. Elsevier Inc.: 2016; p 300. 
13. Al-Salem, S. M.; Lettieri, P.; Baeyens, J., Recycling and recovery routes of plastic solid waste (PSW): a review. Waste Manag 2009, 29, (10), 2625-43.

527 14. Nakajima-Kambe, T., Ichihashi, F., Matsuzoe, R., Kato, S., and Shintani, N.,

Degradation of aliphatic-aromatic co-polyesters by bacteria that can degrade aliphatic polyesters. Polym. Degrad. Stab. 2009, 94, 1901-1905.

15. Niaounakis, M., Biopolymers Reuse, Recycling, and Disposal. Elsevier Inc.: Amsterdam, 2013; p 413.

16. Kobayashi, S.; Uyama, H.; Takamoto, T., Lipase-catalyzed degradation of polyesters in organic solvents, a new methodology of polymer recycling using enzyme as catalyst. Biomacromolecules 2000, 1, (1), 3-5.

17. Russell, J. R.; Huang, J.; Anand, P.; Kucera, K.; Sandoval, A. G.; Dantzler, K. W.; Hickman, D.; Jee, J.; Kimovec, F. M.; Koppstein, D.; Marks, D. H.; Mittermiller, P. A.; Nunez, S. J.; Santiago, M.; Townes, M. A.; Vishnevetsky, M.; Williams, N. E.; Vargas, M. P.; Boulanger, L. A.; Bascom-Slack, C.; Strobel, S. A., Biodegradation of polyester polyurethane by endophytic fungi. Appl Environ Microbiol 2011, 77, (17), 6076-84.

18. Maeda, H.; Yamagata, Y.; Abe, K.; Hasegawa, F.; Machida, M.; Ishioka, R.; Gomi, K.; Nakajima, T., Purification and characterization of a biodegradable plasticdegrading enzyme from Aspergillus oryzae. Appl Microbiol Biotechnol 2005, 67, (6), 778-88.

19. Jarerat, A., Pranamuda, H., and Tokiwa, Y., Poly (LOlactide)-degrading activity in various actinomycetes. Macromol. Biosci. 2002, 2, 420-428.

20. Akutsu-Shigeno, Y.; Teeraphatpornchai, T.; Teamtisong, K.; Nomura, N.; Uchiyama, H.; Nakahara, T.; Nakajima-Kambe, T., Cloning and sequencing of a poly(DL-lactic acid) depolymerase gene from Paenibacillus amylolyticus strain TB-13 and its functional expression in Escherichia coli. Appl Environ Microbiol 2003, 69, (5), 2498-504.

21. Kleeberg, I.; Welzel, K.; Vandenheuvel, J.; Muller, R. J.; Deckwer, W. D., Characterization of a new extracellular hydrolase from Thermobifida fusca degrading aliphatic-aromatic copolyesters. Biomacromolecules 2005, 6, (1), 262-70.

22. Tchigvintsev, A.; Tran, H.; Popovic, A.; Kovacic, F.; Brown, G.; Flick, R.; Hajighasemi, M.; Egorova, O.; Somody, J. C.; Tchigvintsev, D.; Khusnutdinova, A.; Chernikova, T. N.; Golyshina, O. V.; Yakimov, M. M.; Savchenko, A.; Golyshin, P. N.; Jaeger, K. E.; Yakunin, A. F., The environment shapes microbial enzymes: five coldactive and salt-resistant carboxylesterases from marine metagenomes. Appl Microbiol Biotechnol 2015, 99, (5), 2165-78.

23. Perz, V.; Baumschlager, A.; Bleymaier, K.; Zitzenbacher, S.; Hromic, A.; Steinkellner, G.; Pairitsch, A.; Lyskowski, A.; Gruber, K.; Sinkel, C.; Kuper, U.; Ribitsch, D.; Guebitz, G. M., Hydrolysis of synthetic polyesters by Clostridium botulinum esterases. Biotechnol Bioeng 2016, 113, (5), 1024-34.

24. Mayumi, D.; Akutsu-Shigeno, Y.; Uchiyama, H.; Nomura, N.; Nakajima-Kambe, T., Identification and characterization of novel poly(DL-lactic acid) depolymerases from metagenome. Appl Microbiol Biotechnol 2008, 79, (5), 743-50.

25. Muller, C. A.; Perz, V.; Provasnek, C.; Quartinello, F.; Guebitz, G. M.; Berg, G., Discovery of Polyesterases from Moss-Associated Microorganisms. Appl Environ Microbiol 2017, 83, (4). 
26. Purdy, R. E.; Kolattukudy, P. E., Hydrolysis of plant cuticle by plant pathogens.

Purification, amino acid composition, and molecular weight of two isozymes of cutinase and a nonspecific esterase from Fusarium solani f. pisi. Biochemistry 1975, 14, (13), 2824-31.

27. Liu, Z.; Gosser, Y.; Baker, P. J.; Ravee, Y.; Lu, Z.; Alemu, G.; Li, H.; Butterfoss, G. L.; Kong, X. P.; Gross, R.; Montclare, J. K., Structural and functional studies of Aspergillus oryzae cutinase: enhanced thermostability and hydrolytic activity of synthetic ester and polyester degradation. J Am Chem Soc 2009, 131, (43), 15711-6.

28. Ferrario, V., Pellis, A., Cespugli, M., Guebitz, G.M., and Gardossi, L., Nature inspired solutions for polymers: will cutinase enzymes make polyesters and polyamides greener? Catalysts 2016, 6, 205.

29. Sulaiman, S.; Yamato, S.; Kanaya, E.; Kim, J. J.; Koga, Y.; Takano, K.; Kanaya, S., Isolation of a novel cutinase homolog with polyethylene terephthalate-degrading activity from leaf-branch compost by using a metagenomic approach. Appl Environ Microbiol 2012, 78, (5), 1556-62.

30. Schmidt, J., Wei, R., Oeser, T., Silva, L.A.D., Breite, D., Schulze, A., and Zimmermann, W., Degradation of polyester polyurethane by bacterial polyester hydrolases. Polymers 2017, 9, 65.

31. Kold, D.; Dauter, Z.; Laustsen, A. K.; Brzozowski, A. M.; Turkenburg, J. P.; Nielsen, A. D.; Koldso, H.; Petersen, E.; Schiott, B.; De Maria, L.; Wilson, K. S.; Svendsen, A.; Wimmer, R., Thermodynamic and structural investigation of the specific SDS binding of Humicola insolens cutinase. Protein Sci 2014, 23, (8), 1023-35.

32. Sulaiman, S.; You, D. J.; Kanaya, E.; Koga, Y.; Kanaya, S., Crystal structure and thermodynamic and kinetic stability of metagenome-derived LC-cutinase. Biochemistry 2014, 53, (11), 1858-69.

33. Hajighasemi, M.; Nocek, B. P.; Tchigvintsev, A.; Brown, G.; Flick, R.; Xu, X.; Cui, H.; Hai, T.; Joachimiak, A.; Golyshin, P. N.; Savchenko, A.; Edwards, E. A.; Yakunin, A. F., Biochemical and Structural Insights into Enzymatic Depolymerization of Polylactic Acid and Other Polyesters by Microbial Carboxylesterases. Biomacromolecules 2016, 17, (6), 2027-39.

34. Herrero Acero, E.; Ribitsch, D.; Dellacher, A.; Zitzenbacher, S.; Marold, A.; Steinkellner, G.; Gruber, K.; Schwab, H.; Guebitz, G. M., Surface engineering of a cutinase from Thermobifida cellulosilytica for improved polyester hydrolysis. Biotechnol Bioeng 2013, 110, (10), 2581-90.

35. Gonzalez, C. F.; Proudfoot, M.; Brown, G.; Korniyenko, Y.; Mori, H.; Savchenko, A. V.; Yakunin, A. F., Molecular basis of formaldehyde detoxification. Characterization of two S-formylglutathione hydrolases from Escherichia coli, FrmB and YeiG. J Biol Chem 2006, 281, (20), 14514-22.

36. Lemak, S.; Tchigvintsev, A.; Petit, P.; Flick, R.; Singer, A. U.; Brown, G.; Evdokimova, E.; Egorova, O.; Gonzalez, C. F.; Chernikova, T. N.; Yakimov, M. M.; Kube, M.; Reinhardt, R.; Golyshin, P. N.; Savchenko, A.; Yakunin, A. F., Structure and activity of the cold-active and anion-activated carboxyl esterase OLEI01171 from the oildegrading marine bacterium Oleispira antarctica. Biochem J 2012, 445, (2), 193-203.

615 Deck, L. M.; Royer, R. E.; Piper, R. C.; Dame, J. B.; Makler, M. T.; Vander Jagt, D. L., 
616 Comparative structural analysis and kinetic properties of lactate dehydrogenases from the 617 four species of human malarial parasites. Biochemistry 2004, 43, (20), 6219-29.

618 38. Jun, C.; Sa, Y. S.; Gu, S. A.; Joo, J. C.; Kim, S.; Kim, K. J.; Kim, Y. H.,

619 Discovery and characterization of a thermostable D-lactate dehydrogenase from

620 Lactobacillus jensenii through genome mining. Process Biochem 2013, 48, (1), 109-117.

621 39. Sievers, F.; Wilm, A.; Dineen, D.; Gibson, T. J.; Karplus, K.; Li, W.; Lopez, R.;

622 McWilliam, H.; Remmert, M.; Soding, J.; Thompson, J. D.; Higgins, D. G., Fast, scalable generation of high-quality protein multiple sequence alignments using Clustal Omega. Mol Syst Biol 2011, 7, 539.

40. Tamura, K.; Stecher, G.; Peterson, D.; Filipski, A.; Kumar, S., MEGA6:

Molecular Evolutionary Genetics Analysis version 6.0. Mol Biol Evol 2013, 30, (12), 2725-9.

628 41. Teeraphatpornchai, T.; Nakajima-Kambe, T.; Shigeno-Akutsu, Y.; Nakayama, M.; Nomura, N.; Nakahara, T.; Uchiyama, H., Isolation and characterization of a bacterium that degrades various polyester-based biodegradable plastics. Biotechnol Lett 2003, 25, (1), 23-8.

632 42. Babson, A. L.; Phillips, G. E., A rapid colorimetric assay for serum lactic dehydrogenase. Clin Chim Acta 1965, 12, (2), 210-5.

43. Codari, F.; Moscatelli, D.; Storti, G.; Morbidelli, M., Characterization of LowMolecular-Weight PLA using HPLC. Macromol Mater Eng 2010, 295, (1), 58-66.

636 44. Rosenbaum, G.; Alkire, R. W.; Evans, G.; Rotella, F. J.; Lazarski, K.; Zhang, R. 637 G.; Ginell, S. L.; Duke, N.; Naday, I.; Lazarz, J.; Molitsky, M. J.; Keefe, L.; Gonczy, J.;

638 Rock, L.; Sanishvili, R.; Walsh, M. A.; Westbrook, E.; Joachimiak, A., The Structural

639 Biology Center 19ID undulator beamline: facility specifications and protein

640 crystallographic results. J Synchrotron Radiat 2006, 13, (Pt 1), 30-45.

641 45. Minor, W.; Cymborowski, M.; Otwinowski, Z.; Chruszcz, M., HKL-3000: the

642 integration of data reduction and structure solution--from diffraction images to an initial

643

644 model in minutes. Acta Crystallogr D 2006, 62, (Pt 8), 859-66.

46. Adams, P. D.; Afonine, P. V.; Bunkoczi, G.; Chen, V. B.; Davis, I. W.; Echols, N.; Headd, J. J.; Hung, L. W.; Kapral, G. J.; Grosse-Kunstleve, R. W.; McCoy, A. J.; Moriarty, N. W.; Oeffner, R.; Read, R. J.; Richardson, D. C.; Richardson, J. S.; Terwilliger, T. C.; Zwart, P. H., PHENIX: a comprehensive Python-based system for macromolecular structure solution. Acta Crystallogr D 2010, 66, (Pt 2), 213-21.

651 48. Chen, V. B.; Arendall, W. B., 3rd; Headd, J. J.; Keedy, D. A.; Immormino, R. M.; 652 Kapral, G. J.; Murray, L. W.; Richardson, J. S.; Richardson, D. C., MolProbity: all-atom 653 structure validation for macromolecular crystallography. Acta Crystallogr D 2010, 66, (Pt 654 1), 12-21.

655 49. Dolinsky, T. J.; Czodrowski, P.; Li, H.; Nielsen, J. E.; Jensen, J. H.; Klebe, G.;

656 Baker, N. A., PDB2PQR: expanding and upgrading automated preparation of

657 biomolecular structures for molecular simulations. Nucleic Acids Res 2007, 35, (Web

658 Server issue), W522-5.

659 50. Baker, N. A.; Sept, D.; Joseph, S.; Holst, M. J.; McCammon, J. A., Electrostatics 660 of nanosystems: application to microtubules and the ribosome. Proc Natl Acad Sci U S A 661 2001, 98, (18), 10037-41. 
51. Hutchinson, E. G.; Thornton, J. M., HERA-A program to draw schematic diagrams of protein secondary structures. Proteins: Structure, Function, and

664 Bioinformatics 1990, 8, (3), 203-212.

665 52. Laskowski, R. A., PDBsum new things. Nucleic Acids Research 2009, 37,

666 (Database issue), D355-D359.

667 53. Popovic, A.; Hai, T.; Tchigvintsev, A.; Hajighasemi, M.; Nocek, B.;

668 Khusnutdinova, A. N.; Brown, G.; Glinos, J.; Flick, R.; Skarina, T.; Chernikova, T. N.;

669 Yim, V.; Bruls, T.; Paslier, D. L.; Yakimov, M. M.; Joachimiak, A.; Ferrer, M.;

670 Golyshina, O. V.; Savchenko, A.; Golyshin, P. N.; Yakunin, A. F., Activity screening of environmental metagenomic libraries reveals novel carboxylesterase families. Sci Rep 2017, 7, 44103. 54. Masaki, K.; Kamini, N. R.; Ikeda, H.; Iefuji, H., Cutinase-like enzyme from the yeast Cryptococcus sp. strain S-2 hydrolyzes polylactic acid and other biodegradable plastics. Appl Environ Microbiol 2005, 71, (11), 7548-50.

55. Kodama, Y.; Masaki, K.; Kondo, H.; Suzuki, M.; Tsuda, S.; Nagura, T.; Shimba, N.; Suzuki, E.; Iefuji, H., Crystal structure and enhanced activity of a cutinase-like enzyme from Cryptococcus sp. strain S-2. Proteins 2009, 77, (3), 710-7.

56. Kawai, F., Polylactic acid (PLA)-degrading microorganisms and PLA depolymerases. In Green Polymer Chemistry: Biocatalysis and Biomaterials., Cheng, H. N., and Gross, R.A., Ed. ACS 2010; pp 405-414.

682 57. Kawai, F., Nakadai, K., Nishioka, E., Nakajima, H., Ohara, H., Masaki, K., and

683 Iefuju, H., Different enantioselectivity of two types of poly(lactic acid) depolymerases

684 toward poly(L-lactic acid) and poly(D-lactic acid). Polym. Degrad. Stab. 2011, 96, 13426851348.

686 58. Perz, V.; Baumschlager, A.; Bleymaier, K.; Zitzenbacher, S.; Hromic, A.;

687 Steinkellner, G.; Pairitsch, A.; Łyskowski, A.; Gruber, K.; Sinkel, C.; Küper, U.;

688 Ribitsch, D.; Guebitz, G. M., Hydrolysis of synthetic polyesters by Clostridium botulinum esterases. Biotechnology and Bioengineering 2016, 113, (5), 1024-1034. 59. Biundo, A.; Hromic, A.; Pavkov-Keller, T.; Gruber, K.; Quartinello, F.; Haernvall, K.; Perz, V.; Arrell, M. S.; Zinn, M.; Ribitsch, D.; Guebitz, G. M., Characterization of a poly(butylene adipate-co-terephthalate)-hydrolyzing lipase from Pelosinus fermentans. Appl Microbiol Biot 2016, 100, (4), 1753-1764. 60. Liu, Z.; Gosser, Y.; Baker, P. J.; Ravee, Y.; Lu, Z.; Alemu, G.; Li, H.; Butterfoss, G. L.; Kong, X.-P.; Gross, R.; Montclare, J. K., Structural and Functional Studies of Aspergillus oryzae Cutinase: Enhanced Thermostability and Hydrolytic Activity of Synthetic Ester and Polyester Degradation. Journal of the American Chemical Society 2009, 131, (43), 15711-15716.

61. Longhi, S.; Czjzek, M.; Lamzin, V.; Nicolas, A.; Cambillau, C., Atomic resolution $(1.0 \AA)$ crystal structure of Fusarium solani cutinase: stereochemical analysis11Edited by R. Huber. Journal of Molecular Biology 1997, 268, (4), 779-799. 62. Rozeboom, H. J.; Godinho, L. F.; Nardini, M.; Quax, W. J.; Dijkstra, B. W., Crystal structures of two Bacillus carboxylesterases with different enantioselectivities. Biochim Biophys Acta 2014, 1844, (3), 567-75. of a Novel Thermophilic Esterase from the Planctomycetes Species, Thermogutta 
terrifontis Reveals an Open Active Site Due to a Minimal 'Cap' Domain. Front Microbiol 2015, 6, 1294.

Phyre2 web portal for protein modeling, prediction and analysis. Nat Protoc 2015, 10,

712 65. Arpigny, J. L.; Jaeger, K. E., Bacterial lipolytic enzymes: classification and 713 properties. Biochem J 1999, 343 Pt 1, 177-83.

714 66. Kumar, S.; Stecher, G.; Tamura, K., MEGA7: Molecular Evolutionary Genetics

715 Analysis Version 7.0 for Bigger Datasets. Molecular Biology and Evolution 2016, 33,

716 (7), 1870-1874.

717 67. Zuckerkandl, E.; Pauling, L., Evolutionary divergence and convergence in

718 proteins. Evolving genes and proteins 1965, 97, 97-166.

Table 1. Kinetic parameters of purified MGS0156 and GEN0105 with soluble mono-

ester substrates. Results are means \pm SD from at least two independent determinations.

\begin{tabular}{|c|c|c|c|c|}
\hline Protein & Variable substrate & $\boldsymbol{K}_{\mathbf{m}}(\mathbf{m M})$ & $\boldsymbol{k}_{\text {cat }}\left(\mathbf{s}^{\mathbf{1}}\right)$ & $\begin{array}{c}\boldsymbol{k}_{\text {cat }} / \boldsymbol{K}_{\mathbf{m}} \\
\left(\mathbf{s}^{-1} \mathbf{M}^{-\mathbf{1}}\right)\end{array}$ \\
\hline \multirow{7}{*}{} & $\alpha$-Naphthyl acetate (C2) & $0.16 \pm 0.02$ & $130 \pm 5$ & $8.1 \times 10^{5}$ \\
\cline { 2 - 5 } & $\alpha$-Naphthyl propionate (C3) & $0.050 \pm 0.005$ & $155 \pm 4$ & $3.1 \times 10^{6}$ \\
\cline { 2 - 5 } & $\alpha$-Naphthyl butyrate (C4) & $0.065 \pm 0.004$ & $115 \pm 7$ & $1.8 \times 10^{6}$ \\
\cline { 2 - 5 } & $p$ NP-acetate (C2) & $0.161 \pm 0.018$ & $450 \pm 21$ & $2.8 \times 10^{6}$ \\
\cline { 2 - 5 } & $p$ NP-propionate (C3) & $0.055 \pm 0.005$ & $419 \pm 11$ & $7.6 \times 10^{6}$ \\
\cline { 2 - 5 } & $p$ NP-butyrate (C4) & $0.058 \pm 0.006$ & $635 \pm 24$ & $1.1 \times 10^{7}$ \\
\cline { 2 - 5 } & $p$ NP-valerate (C5) & $0.036 \pm 0.002$ & $474 \pm 8$ & $1.3 \times 10^{7}$ \\
\cline { 2 - 5 } & $p$ NP-octanoate (C8) & $0.145 \pm 0.009$ & $1101 \pm 26$ & $7.6 \times 10^{6}$ \\
\cline { 2 - 5 } & $p$ NP-decanoate (C10) & $0.32 \pm 0.03$ & $775 \pm 33$ & $2.4 \times 10^{6}$ \\
\cline { 2 - 5 } & $p$ NP-laurate (C12) & $0.13 \pm 0.01$ & $116 \pm 5$ & $0.9 \times 10^{6}$ \\
\cline { 2 - 5 } & $p$ NP-myristate (C14) & $0.31 \pm 0.17$ & $68 \pm 3$ & $0.2 \times 10^{6}$ \\
\cline { 2 - 5 } & $p$ NP-palmitate (C16) & $0.108 \pm 0.004$ & $31.0 \pm 0.5$ & $0.3 \times 10^{6}$ \\
\hline GEN0105 & $\alpha$-Naphthyl propionate (C3) & $0.602 \pm 0.09$ & $88.79 \pm 5$ & $1.5 \times 10^{5}$ \\
\hline
\end{tabular}


727 polyesters. The presence of polyesterase activity was analyzed using agarose-based

728 assays with the indicated emulsified polyesters.

\begin{tabular}{|c|c|c|c|c|}
\hline Polyesters & GEN0105 & GEN0160 & MGS0084 & MGS0156 \\
\hline 1. $\operatorname{PLA}(\mathrm{D}, \mathrm{L}) ; \mathrm{M}_{\mathrm{w}} 2 \mathrm{~K}$ & + & - & + & + \\
\hline 2. $\operatorname{PLA}(\mathrm{D}, \mathrm{L}) ; \mathrm{M}_{\mathrm{w}} 10 \mathrm{~K}$ & + & - & - & + \\
\hline 3. PLA $(\mathrm{D}, \mathrm{L}) ; \mathrm{M}_{\mathrm{w}} 10 \mathrm{~K}, \mathrm{ET}^{\mathrm{a}}$ & + & - & - & + \\
\hline 4. PLA $(\mathrm{D}, \mathrm{L}) ; \mathrm{M}_{\mathrm{w}} 18 \mathrm{~K}$ & + & - & - & + \\
\hline 5. PLA $(\mathrm{D}, \mathrm{L}) ; \mathrm{M}_{\mathrm{w}} 70 \mathrm{~K}$ & + & - & - & + \\
\hline 6. PLA (L); $\mathrm{M}_{\mathrm{w}} 40 \mathrm{~K}$ & + & - & - & - \\
\hline 7. PLA (L); ester term & + & - & - & - \\
\hline 8. PLA (D); $\mathrm{M}_{\mathrm{w}} 124 \mathrm{~K}$ & - & - & - & - \\
\hline 9. Ingeo ${ }^{\mathrm{TM}}$ PLA6400 & + & - & - & - \\
\hline 10. Ingeo ${ }^{\mathrm{TM}}$ PLA4032 & - & - & - & - \\
\hline 11. PLGA $^{b}$ & + & - & + & + \\
\hline 12. $\mathrm{PHB}$ & - & - & - & - \\
\hline 13. PHBV & + & - & - & - \\
\hline 14. PCL; $\mathrm{M}_{\mathrm{w}} 10 \mathrm{~K}$ & + & + & + & + \\
\hline 15. PCL; $\mathrm{M}_{\mathrm{w}} 45 \mathrm{~K}$ & + & + & + & + \\
\hline 16. PCL; $\mathrm{M}_{\mathrm{w}} 70 \mathrm{~K}$ & + & + & + & + \\
\hline 17. Bionolle ${ }^{\mathrm{TM}}$ PBS 1001MD & - & - & - & - \\
\hline 18. Bionolle ${ }^{\mathrm{TM}}$ PBS 1020MD & - & - & - & - \\
\hline 19. Bionolle ${ }^{\mathrm{TM}}$ PBSA 3001MD & + & + & + & + \\
\hline 20. Bionolle ${ }^{\mathrm{TM}}$ PBSA 3020MD & + & + & + & + \\
\hline 21. PES & + & + & + & + \\
\hline 22. 3PET & + & - & - & + \\
\hline
\end{tabular}

$730 \quad{ }^{a}$ ET, ester terminated.

$731 \quad{ }^{\mathrm{b}}$ PLGA,... 


\section{Figure Legends}

733 Figure 1. Polyesterase activity of purified metagenomic carboxylesterases. Agarose-

734 based screen of purified proteins for the presence of polyesterase activity against

735 emulsified PCL10. The presence of polyesterase activity is indicated by the formation of

736 a clear zone around the wells containing purified proteins (50 $\mu \mathrm{g}$ of protein/well, 72 hours

737 at $\left.30{ }^{\circ} \mathrm{C}\right)$. Agarose (1.5\%) plates contained $0.2 \%$ emulsified PCL10 in $50 \mathrm{mM}$ Tris-HCl

738 (pH 8.0) buffer. PlaM4, a previously characterized polyester hydrolase (ref?), and porcine

739 liver esterase (PLE) were used as positive and negative controls, respectively.

740 Figure 2. Phylogenetic analysis of metagenomic polyesterases. Phylogenetic tree of

741 polyesterases showing their relatedness to known esterase families (I - VIII, based on

742 Arpigny and Jaeger, 1999). ${ }^{65}$ The phylogenetic tree was generated by the MEGA7

743 software package ${ }^{66}$ using the neighbor-joining method. The numbers on the nodes

744 correspond to the percent recovery from 1,000 bootstrap resamplings. Evolutionary

745 distances were calculated using the Poisson correction method ${ }^{67}$, and are in the units of

746 the number of amino acid substitutions per site. GenBank accession numbers or Uniprot

747 IDs are shown in parentheses.

748 Figure 3. Esterase activity of metagenomic polyesterases against soluble monoester

749 substrates of varying acyl chain length. Reaction mixtures contained $0.5 \mathrm{mM} p$ -

750 nitrophenyl ( $p \mathrm{NP})$ - or $1.5 \mathrm{mM} \alpha$-naphthyl $(\alpha \mathrm{N})$ esters of varying chain lengths, and 0.01

$751 \mu \mathrm{g}$ of purified MGS0156 (A) or GEN0105 (B). The white bars show activity against $\alpha$ -

752 naphthyl esters, whereas the gray bars represent activity against $p \mathrm{NP}$ - substrates. 
754 Figure 4. Production of lactic acid during incubation of solid PLA10 with purified

755 metagenomic polyesterases: wild-type MGS0156 (A), GEN0105 (B) and MGS0156

756 L169A (C). Monomeric and oligomeric lactic acid products were measured using D- and

757 L-lactate dehydrogenases as described in Materials and Methods. Results are means \pm SD

758 from at least two independent determinations.

759 Figure 5. LC-MS analysis of reaction products for solid PLA hydrolysis by purified

760 MGS0156 and GEN0105. Reaction mixtures (1.0 ml) contained $12 \mathrm{mg}$ of solid PLA10

761 and $50 \mu \mathrm{g}$ of purified enzyme in $0.4 \mathrm{M}$ Tris- $\mathrm{HCl}(\mathrm{pH}$ 8.0). Samples were collected after

$762 \mathrm{O} / \mathrm{N}$ incubation at $30^{\circ} \mathrm{C}$, filtered by centrifugation and analysed by LC-MS as described

763 in Materials and Methods. Each peak is labelled with a number representing the

764 oligomeric state of the polyester species. Results are means \pm SD from at least two

765 independent determinations.

766 Figure 6. Crystal structure of MGS0156. (A) Overall fold of the MGS0156 protomer

767 shown in three views related by a $90^{\circ}$ rotation. The protein core $\beta$-sheet is shown in cyan

768 with $\alpha$-helices colored in grey, and the lid domain in magenta. The position of the active

769 site is indicated by the side chain of the catalytic Ser232. (B) Two views of the MGS0156

770 dimer related by a $90^{\circ}$ rotation. The two protomers are colored in cyan and magenta. (C)

771 Two surface presentation of the protein tetramer shown in two views related by $90^{\circ}$

772 rotation. The protomers are shown in different colors, and the active site openings are

773 indicated by arrows.

774 Figure 7. Close-up view of the MGS0156 active site. The protein ribbon is colored in

775 gray with amino acid side chains shown as sticks and carbon atoms colored in green. 
776 Only the side chains of catalytic triad and residues potentially involved in substrate

777 binding are shown.

778 Figure 8. Mutational analysis of MGS0156: hydrolytic activity of purified mutant

779 proteins against mono- and polyester substrates. (A), Agarose-based screen showing

780 polyesterase activity against emulsified PCL10. (B), Monoesterase activity against $\alpha$ -

781 naphthyl acetate ( $2 \mathrm{mM}, 0.02 \mu \mathrm{g}$ protein/assay, white bars) and polyesterase activity

782 against solid PLA10 measured using LDH assay (??? $\mu$ g protein/assay, gray bars).

783 